\title{
DAMPAK ERA DIGITAL BAGI PERTUMBUHAN IMAN KRISTEN PPGT DI JEMAAT PALI
}

\author{
Dewi Mangolo \\ Institute Agama Kristen Negeri Toraja \\ Dewimangolo17@gmail.com
}

\begin{abstract}
Abstrak: era digital memberikan pengaruh yang begitu besar bagi kehidupan tiap orang, termasuk bagi pertumbuhan Iman PPGT di Jemaat Pali. Jenis penelitian yang digunakan adalah penelitian deskriptif yang bertujuan untuk memberikan suatu fakta mengenai sesuatu hal di timbulkan di era digital sekarang ini yang memberikan dampat terhadap pertumbuhan iman Kristen bagi PPGT jemaat Pali. Adapun tujuan dari penulisan ini adalah agar para pemuda-pemudi tidak terbawa arus negatif dari era digital sehingga tidak mengalami kemerosotan iman dan manfaatnya yakni mereka terus bertumbuh berakar didalam Kritus dan menjadi generasi Gereja yang berkarakter Kristiani.
\end{abstract}

Kata kunci: era digital, pertumbuhan Iman, Dampak Era digital

\section{PENDAHULUAN}

Munculnya era digital, proses komunikasi semakin cepat, ruang diskusi semakin terbuka, berbeda pada media masa konvensional yang masi sangat terbatas hanya hanya menggunakan buku, surat kabar, radio dan televisi. Perkembangan teknologi kini merubah media massa dan perilaku masyarakatnya. ${ }^{1}$ Dan bahkan di era modern saat ini, lapisan masyarakat tanpa mengenal batas usia di pengaruhi oleh adanya perkembangan media yang cukup pesat. ${ }^{2}$ Indonesia adalah salah satu negara yang mengalami perkembangan teknologi secara global. Revolusi industri 4.0

\footnotetext{
${ }^{1}$ M. Tata Taufik, Dakwa Era Digital: Sejarah, Metode dan Perkembangan, Kuningan: Pustaka Al-Ikhlash, 2020. 111

${ }^{2}$ Yosua Feliciano Camerling, et al, " Gereja Bermisi Melalui Media Digital di Era Revolusi Industri 4.0," Visio Dei: Jurnal Teologi Kristen ( Juni 2020): 2
} 
yang terjadi di Eropa kini Indonesia pun terdampak. Informasi sangat cepat beredar dikalangan masyarakat dengan penggunaan media sosial. ${ }^{3}$

Realita yang tak terhindari oleh siapa pun atau institus yang hidup dalam konteks globalisasi dan masyarakat network society yang artinya berjejaring akibat perkembangan tekologi digital. Teknologi yang kita gunakan saat ini menggunakan sistem digital sebagai basi datanya hal ini dituliskan oleh Mark Chan. Teknologi sudah menjadi kebutuhan manusia yang tak tergantikan pada zaman ini, karena semuanya sudah serba praktis dan teknologi berperan penting sehingga manusia modern secara parktis tidak lagi dapat hidup tanpa teknologi. Dan hal itu dapat dibuktikan melalui perubahan gaya hidup manusia menjadi gaya hidup yang lebih mudah, efektif, efesien, nyaman namun juga memiliki resiko.

\section{Tujuan dan manfaat penulisan}

Tujuan penulisan adalah agar para pemuda-pemudi tidak terbawa arus negatif dari era digital sehingga tidak mengalami kemerosotan iman dan manfaatnya yakni mereka terus bertumbuh berakar didalam Kritus dan menjadi generasi Gereja yang berkarakter Kristiani.

\section{Metode Penelitian}

Dalam melakukan penelitian untuk mendapatkan data-data yang akurat makan proses penelitian menggunakan pendekatan kualitatif, pemelihan pendekatan kualitatif ini akan memberikan suatu pemahaman, pengertian tentang suatu fenomena yang terjadi dilapangan dengan berfokus pada perilaku anak mudah khususnya PPGT jemaat Pali di era digital dengan pertumbuhan imannya.

\section{Perkembangan digitalisasi}

Para teoritis, moralitas, dan analis mencoba menjelaskan mengenai perkembangan Teknologi Digital bahwa ada hubungan antara kebangkitan The Net Generation dengan

\section{(2019): 1}

${ }^{3}$ Daniel Fajar Panuntun, “ Misi Apologetika Kristen Online di Era Dirupsi,” Jurnal Apostolos, vol 2 no 1 
fenomena "kemerosotan anak mudah". ${ }^{4}$ berikut dampak negatif yang ditimbulkan era digital diantarnya;

1. Pengaksesan data yang cukup mudah berpotensi menyebabkan orang melakukan kecurangan atau plagiasi terhadap karya seseorang

2. Anak-anak akan cenderung berfikir pendek

3. Penyalagunaan pengetahuan melalui media internet dapat digunakan untuk melakukan pencurian, menerobos sistem perbankan, dan lain sebagainya

4. Penggunaan teknologi informasi tidak dipergunakan secara efektif sebagai sarana belajar, tetapi digunakan untuk mencari informasi atau konten-konten yang dapat meruskan moralistan seseorang. ${ }^{5}$

Dampak negatif dari era digital tentu akan mempengaruhi pertembuhan iman Kristen khususnya bagi para muda-mudi. Dalam hal ini penulis akan berfokus pada Persekutuan Pemuda Gereja Toraja (PPGT) yang ada di Jemaat Pali dimana anggota PPGT yakni yang berusia 15-30 tahun. Dimana rata-rata sudah menjadi pengguna teknologi informasi di era modern. Jemaat ini berada di Kecamatan Bittuang, Kabupaten Tana Toraja.

\section{Pertumbuhan iman Kristen}

Pertumbuhan dalam bahasa Yunani " Auxano" menjadikan bertumbuh atau meningkatkan reputasi, pengaru yang positif. Dalam Kitab I Korintus 3:6 berkata bahwa “ Aku menanam, Apolos meyiram tetapi Allah yang memberi pertumbuhan.” Efesus 3:20 “ Bagi Dialah, yang dapat melakukan jauh lebih banyak dari pada yang kita Doakan atau pikirkan, seperti yang ternyata dari kuasa yang bekerja di dalam kita,”. Tanpa Tuhan tidak ada pertumbuhan dan tidak ada hasil dari usaha manusia.

Pada hakekatnya pertumbuhan iman merupakan suatu hal yang asalanya daripada Tuhan dan yang menjadi tugas manusia adalah respon positif terhadap karya Roh Kudus itu. Iman yang bertumbuh akan menghasilkan buah yang baik yaitu buah Roh yang nampak melalui kehiduapan

\footnotetext{
${ }^{4}$ Ronal Paul Sitompul, “ Pelayanan Pemuda di Era Teknologi Digital,” Jurnal Antusias; vol 5, no.l (Juni 2017): 3-6

${ }^{5}$ Maulidya Ulfah, Digital Parenting, Jawa Barat: Edu Publisher, 2020. 76
} 
setiap harinya sambil menantikan panggilan Tuhan. Kekristenan seringkali digambarkan sesuatu yang memberikan dampak yang baik, orang Kristen tampak sebagai sesutu yang hidup, bertumbuh, berproses seperti tumbuhan yang berakar serta berbuah. Jadi apa yang dimaksudkan pertumbuhan iman kristen adalah hal keadaan yang hidup dan berkembang dalam kepercayaan kepada Tuhan serta menantikan panggila-Nya, dan apa yang menjadi bukti dari kepercayaannya itu ialah ketika dapat menghasilkan buah. ${ }^{6}$

Tanpa Respon dari manusia makan tidak ada pertumbuhan iman seperti yang telah di katakan diatas, menurut Prof. Hembing bahwa manusia yang hidup dalam keadaan iman yang tidak bertumbuh atau kemerosotan iman, akal, moral, dan mental bila menghadapi tantangan zaman serta hal-hal yang tidak cocok dengan hawa nafsu, hal ini akan membuat mereka kekurangan materi dan kemanusiaan, mereka akan hidup dalam ketidak bahagiian, kehilangan harapan, hilangya kepribadian, kawatir, dan cenderung akan mempersalakan keadaan jika mengalamin sebuah kegagalan. Hal ini terjadi karena kehilangan prinsip Iman, mengabaikan asas moralitas dan akhlak, tidak menggunakan akal yang sehat, serta mengabaikan nilai-nilai kemanusiaan dalam setiap kehidupannya, dan pada akhirnya hidup dalam kegelapan yang meluruskan jalan mereka menuju kehancuran. ${ }^{7}$

Di era digital Antonio Spadaro menegaskan bahwa tidak hanya sekedar bagaimana kita mengaplikasikan web/Internet atau teknologi tetapi bagaimana kita hidup semestinya, hidup di era digital ini dengan baik. Era digital bermisi untuk membuat manusia terhubung dengan Internet. Antonio berpendapat bahwa dalam kekristenan, kita harus memilih cara pandang spiritual terhadap web, melihat Yesus yang memanggil manusia untuk lebih bersatu dan terhubung. Dan juga kemajuan teknologi dimaksudkan untuk semakin membuat manusia terhubung satu sama lain dari berbagai belahan dunia. ${ }^{8}$

Tidak dapat dipungkiri bahwa era digital yang sudah merabah ke pelosok-peloksok tanah air khususya Indonesia. Hadirnya teknologi sangat membantu dan membawa manusia mencapai suatu kemajuan yang luar biasa. Dan tidak dapat juga dipungkiri bahwa di saat yang sama kejahatan manusia dan dosa juga memakai kemajuan atas karya manusia ini digunakan untuk

${ }^{6}$ Syukurman Zebua, Sibernetik dalam Kuatilatas Pembelajaran Pendidikan Agama Kristen, Jawa Tengah: Anggota IKAPI, 2019. 68-69

${ }^{7}$ Agus Susanto, Sukses Prof. Hembing, Jakarta: PT Prestasi Insani Indonesia (Prestasi), 2000. 42

${ }^{8}$ Armada Riyanto, Berteologi Baru untuk Indonesia, Yogyakarta: PT Kanisius, 2019. 402 
menyebarkan kejahatan, kekerasan, pornografi yang berpotensi merusak kehidupan umat manusia terutama kepada generasi muda. ${ }^{9}$

\section{Iman Kristen dan Era Digital}

Era digital meliki dua dampak yaitu dampak positif dan dampak negatif, dampat negatifnya ialah masayarakat menjadi cenderung lebih menyukai hal-hal yang instan sehingga membuat masyarakat minim untuk bekerja keras. Selain itu dengan semakin berkembang pesatnya ilmu teknologi membuat orang-orang lebih menyukai interaksi secara tidak langsung dengan alat kominikasi yang di gunakan (smartphone) sehingga membuat masyarakat cenderung apatis terhadap lingkungan sekitar. ${ }^{10}$

Kembali kita melihat perkembangan pada saat ini, permasalahan ini adalah hal yng paling merisihkan dalam kehidupan sehari-hari. Perilaku kenakalan anak-anak remaja zaman sekarang cenderung membuat orang tua dan guru sangat kewalahan., contohnya tawuran,seks, narkoba, dan game online. Kenakalan remaja saat ini lebih meningkat dibandingkan dengan tingkat kejahatan orang dewasa. Kita bisa melihat pada kehidupan nyata tindak kejahatan yang dilakukan oleh orang dewasa saat ini juga sudah bisa kita temukan pada usia remaja, sebagaimana contoh yang telah diterakan diatas masalah-masalah seperti ini sangat mudah kita temukan dimasa sekarang. Seiring berjalannya waktu semakin banyak usia remaja yang berurusan dengan pihak polisi karena kejahatan-kejahatan yang dilakukan. Adapun tindakantindakan seperti ini terjadi pada usia remaja dikarenakan oleh berbagai faktor entah itu keluarga, lingkungan sekitar, bahkan masyarakat. ${ }^{11} \mathrm{Hal}$ inilah juga yang mempengaruhi pertumbuhan iman PPGT Jemaat Pali.

Keinginan untuk berinternet mengakibatkan tak jarang orang mengesampingkan diri sendiri dengan kehidupan rohani dan hubungan relasi dengan Tuhan akan semakin terhambat dan membawa diri larut dalam dosa. Kecanduan internet dengan melibatkan pornografi, pemuasan hawa nafsu amarah dan kebencian (game kekerasan), judi online, merupakan hal yang di benci

\footnotetext{
${ }^{9}$ Tim Penulis RH, Renungan Harian, : Yogyakarta: Yayasan Gloria, 2018. 31

${ }^{10}$ Moch, at al, Literasi Media dan Peradaban Masyarakat, Malang: Publishing Grup,

${ }^{11}$ Philipus Setyanto Kalis Stevanus, Arif Wicaksono, I Putu Ayub Darmawan, Daniel Ronda, Firman Panjaitan, Rannu Sanderan, Benyamin Senduk Sugeha, Fibry Jati Nugroho, Susana Prapunoto, Peniel C.D. Maiaweng, Ivan Thorstein Johannis Wiesmann, Semuel Pattipeilohy, Haryadi Baskor, Literasi Digital Dalam Perspektif Kristen (Tawangmangu, 2018), 17.
} 
oleh Tuhan. Tentu dampak yang di timbulkan dari era digital akan mempengaruhi pertumbahan iman. ${ }^{12}$

\section{Pertumbuhan Iman PPGT Jemaat Pali}

Pada Era digital ini, memberikan dampak yang baik dan buruk bagi Pertumbuhan Iman PPGT Jemaat Pali karena sejak berkembangnya gadjet sebagian dari PPGT Jemaat Pali lebih mementingkan bermain game online dari pada mengikuti ibadah, dampak baik yang diberikan oleh perkembangan digital ini ialah memberikan motivasi kepada PPGT untuk membuat grup diskusi mengenai firman Tuhan dan grup berdoa bersama.

\section{Kesimpulan}

Munculnya era digital, proses komunikasi semakin cepat, ruang diskusi semakin terbuka, berbeda pada media masa konvensional yang masi sangat terbatas hanya hanya menggunakan buku, surat kabar, radio dan televisi. Perkembangan era digital memberikan dampak negative dan positif bagi pertumbuhan iman PPGT Jemaat Pali. karena sejak berkembangnya gadjet sebagian dari PPGT Jemaat Pali lebih mementingkan bermain game online dari pada mengikuti ibadah, dampak baik yang diberikan oleh perkembangan digital ini ialah memberikan motivasi kepada PPGT untuk membuat grup diskusi mengenai firman Tuhan dan grup berdoa bersama

12 Jarot Wijanarko et al, Ayah Baik-lbu Baik Parenting Era digital, Jakarta: Bumi Bintaro Permai, 2016. 14- 



\section{DAFTAR PUSTAKA}

Camerling, Feliciano, Yosua, et al, "Gereha Bermisi Melalui Digital di Era Revolusi Industri 4.0," Visio Dei: Jurnal Teologi Kristen (Juni 2020)

Moch, et al, Literasi Media dan Peradaban Masyarakat, Malang: Publishing Grup

Panuntun, Fajar, Daniel, “ Misi Apologetika Kristen Online di Era Dirupsi,” Jurnal Apostolos, vol 2 no 1 (2019)

Riyanto, Armada, Beteologi Baru untuk Indonesia, Yogyakarta: PT Kanisius, 2019

Setyanto, Philipus Setyanto, Kalis Stevanus, Arif Wicaksono, I Putu Ayub Darmawan, Daniel Ronda, Firman Panjaitan, Rannu Sanderan, Benyamin Senduk Sugeha, Fibry Jati Nugroho, Susana Prapunoto, Peniel C.D. Maiaweng, Ivan Thorstein Johannis Wiesmann, Semuel Pattipeilohy, Haryadi Baskor, Literasi Digital Dalam Perspektif Kristen (Tawangmangu, 2018)

Sitompul, Paul, Ronal, "Pelayanan Pemuda di Era Teknologi Digital, “ Jurnal Antusias; vol 5, no.1 (Juni 2017)

Susanto, Agus, Sukses Prof. Hembing, Jakarta: PT Prestasi Insani Indonesia (Prestasi), 2000

Taufik, Tata. M, Dakwa Era Digital: Sejarah, Metode dan Perkembagan, Kuningan: Pustaka Al-ikhlash, 2020

Tim Penulis RH, Renungan Harian, :Yogyakarta: Yayasan Gloria, 2018

Ulfah, Maulidya, Digital Printing, Jawa Barat: Edu Publisher, 2020

Zebua, Syukurman, Sibernetik Dalam Kualitas Pembelajaran Pendidikan Agama Kristen, Jawa Tengah: IKAPI, 2019 